\title{
A História da Ciência no currículo de Física do Ensino Médio
}

Milene Rodrigues Martins milene r martins@hotmail.com Universidade Estadual de Maringá (UEM) Maringá, Paraná, Brasil

Alessandra Daniela Buffon alessandradbuffon@gmail.com Universidade Estadual de Maringá (UEM), Maringá, Paraná, Brasil

\section{RESUMO}

Este trabalho tem o propósito apresentar como a História da Ciência está presente em três documentos oficias: as Orientações Educacionais Complementares aos Parâmetros Curriculares Nacionais; a Diretriz Curricular de Física e a Base Nacional Curricular Comum. Procura-se, por meio deste artigo, auxiliar o professor de Física a conhecer e a compreender tais orientações a fim de que estas sejam implementadas em sua prática docente. 0 procedimento de análise consistiu na busca de elementos textuais que abordassem a temática "História da Ciência" e "História da Física". Como resultado, observou-se que há uma inserção mais expressiva do tema no decorrer dos anos, conforme os documentos foram sendo atualizados. A História da Ciência foi gradualmente sendo mais inserida nos mesmos, porém de maneira ainda discreta e generalizada. Conclui-se, portanto, que a História da Ciência está a caminhar, contudo a passos lentos, dificultando assim a sua ampla implementação no Ensino Médio.

PALAVRAS-CHAVE: História da ciência. História da física. Currículo. Políticas públicas. 


\section{INTRODUÇÃO}

Nos anos 2000, o Ministério da Educação elaborou, em conjunto com profissionais da educação de todo o País, os Parâmetros Curriculares Nacionais (PCN) para o Ensino Médio seguindo os pressupostos estabelecidos na Lei de Diretrizes e Bases da Educação Nacional (LDB). Os PCNs são pautados em competências básicas que visam a inserção dos jovens da vida adulta, bem como, objetivam difundir os princípios da reforma curricular e orientar o professor, na busca de abordagens e metodologias diferenciadas (BRASIL, 2000).

Já em 2002 foram desenvolvidas as Orientações Curriculares Complementares aos Parâmetros Curriculares Nacionais para o Ensino Médio ( $\mathrm{PCN}+$ ) em um trabalho mais democrático, contando com a colaboração das equipes técnicas dos Sistemas Estaduais de Educação, professores e alunos da rede pública e representantes da comunidade acadêmica (BRASIL, 2002). Tais orientações têm o objetivo de fomentar o diálogo sobre a prática docente entre o professor e escola.

Em 2008, o Estado do Paraná se preocupou com o ensino ofertado nas escolas e com a contribuição de distintas esferas da educação elaborou, no decorrer de um longo período de tempo, textos que compõem as Diretrizes Curriculares da Educação Básica para cada disciplina oferecida na rede estadual de ensino. 0 propósito destas diretrizes é fundamentar o trabalho pedagógico e contribuir de maneira decisiva para o fortalecimento da Educação pública estadual do Paraná (PARANÁ, 2008).

Mais recentemente, o Ministério da Educação propôs a Base Nacional Curricular Comum (BNCC) que já se encontra em sua segunda versão, porém ainda não está finalizada, caracterizando-se como uma proposta preliminar. Este documento é "[...] fruto de um amplo processo de debate e negociação com diferentes atores do campo educacional e com a sociedade brasileira em geral" (BRASIL, 2016, p.24). A finalidade da A BNCC consiste em orientar os sistemas na elaboração de suas propostas curriculares, baseando-se no "[...]direito à aprendizagem e ao desenvolvimento, em conformidade com o que preceituam o Plano Nacional de Educação (PNE) e a Conferência Nacional de Educação (CONAE)" (BRASIL, 2016, p.24).

Ao se debruçar sobre os referidos documentos oficiais que visam orientar a prática docente, percebe-se que os mesmos se baseiam em competências e habilidades que necessitam ser desenvolvidas pelos estudantes. O processo de ensino-aprendizagem de Física requer severa e urgente mudança na metodologia empregada pelo professor a fim de que os procedimentos didático-pedagógico propiciem uma formação mais autônoma e crítica.

Nesse sentido, a história da Física emerge como um campo de possibilidades para se compreender o processo de construção do conhecimento científico. Ao se ensinar a história da Física é possível e aconselhável que sejam apresentados aos estudantes diferentes interpretações de fenômenos e problemas para que os discentes adotem uma postura crítica que os levem a pensar, argumentar e se posicionar, assumindo assim um caráter ativo e reflexivo frente ao conhecimento.

De acordo com Matthews (1995), a inserção da história da Física nos currículos nacionais vem ocorrendo em diversos países, tais como: na Inglaterra, no País do Gales, nos Estados Unidos, na Holanda, na Grã-Bretanha, na Dinamarca e no Canadá, todavia ele enfatiza que essa inserção 
[...] não se trata aqui de uma mera inclusão de componentes de história, filosofia e sociologia (HFS) da ciência como um outro item do programa da matéria, mas trata-se de uma incorporação mais abrangente de temas de história, filosofia e sociologia da ciência na abordagem do programa e do ensino de currículos de ciências que geralmente incluem um item chamado de "A natureza da ciência" (MATTHEWS, 1995, p. 165).

Quando o ensino da dimensão histórica e também epistemológica da Física é deixada de lado, a concepção equivocada e fragmentada da atividade científica é reforçada, acarretando em uma visão positivista do conhecimento científico que, por sua vez, tem implicações diretas no modo como os estudantes entendem e se relacionam com as informações provenientes de diferentes fontes. De acordo com Cachapuz et al. (2011, p. 37),

\begin{abstract}
Somos conscientes da dificuldade que implica falar de uma 'imagem correta' da atividade científica, que parece sugerir a existência de suposto método universal, de um modelo único de desenvolvimento científico. É preciso evitar qualquer interpretação deste tipo, mas não se consegue renunciando a falar das características da atividade científica, mas sim com um esforço consciente para evitar simplismos e deformações claramente contrárias ao que se pode compreender, no sentido amplo, como 'aproximação científica do tratamento de problemas'.
\end{abstract}

Neste prisma, entende-se que as potencialidades do ensino da história da Física residem na possibilidade desta apresentar uma concepção mais adequada e coerente da construção do conhecimento científico superando as deformações conjecturadas presentes no ensino, uma vez que elas transpassam "uma imagem ingênua profundamente afastada do que supõe a construção dos conhecimentos científicos" (CACHAPUZ et al., 2011, p. 38).

Na perspectiva de Cachapuz et al. (2011) as deformações conjecturadas são possivelmente sempre as mesmas, apresentando uma significativa coincidência na frequência em que cada uma é citada. São apontadas como deformações conjecturadas oito visões: visão descontextualizada; concepções individualistas e elitista; concepção empiro-indutivista e ateórica; visão rígida, algorítmica, infalível; visão aproblemática e ahistórica; visão exclusivamente analítica; visão acumulativa, de crescimento lineal; e relações entre distintas visões deformadas da atividade científica e tecnológica.

Ao se estudar e discutir a história da Física é possível situar os conhecimentos físicos no campo das atividades humanas, portanto, passíveis a erros conceituais, observacionais e experimentais, rompendo assim com a ideia de verdade absoluta e irrevogável, desmistificando aspectos referentes a linearidade, neutralidade e objetividade do desenvolvimento da Física, enquanto ciência.

\title{
A HISTÓRIA DA CIÊNCIA NOS DOCUMENTOS OFICIAIS
}

A filosofia da ciência possui uma história e é atribuído, por muitos estudiosos, ao inglês Francis Bacon a responsabilidade de ter inventado o método científico. Ele "[..] foi chamado de "primeiro dos modernos e último dos antigos", "inventor do método experimental", "fundador da ciência moderna e do empirismo" (BACON, 1999, p.5). Para Chalmers (1939, p.19), 
Francis Bacon foi um dos primeiros a tentar articular o que o método da ciência moderna. No início do século XVII, propôs que a meta da ciência era o melhoramento da vida do homem na terra e, para ele, essa meta seria alcançada por meio da coleta de fatos com observação organizada e derivando teorias a partir daí. Desde então, a teoria de Bacon tem sido modificada e aperfeiçoada por alguns e, desafiada, de uma maneira razoavelmente radical, por outros.

Bacon era considerado um crítico da ciência e da filosofia e defendia que o debate científico se encontrava submerso em meio a concepções teológicas e infestado de senso comum, crendices e pressupostos metafísicos que não levavam a lugar algum (OSTERMANN; CAVALCANTI, 2011, p. 20), para esses autores

[...] a ciência deve se basear não em meras especulações teóricas, em
metafísica ou mesmo na criatividade. Deve sim, se basear na experimentação
e na indução (partindo-se dos fatos concretos e particulares, como aparecem
na experiência, elevamo-nos até as formas gerais, que constituem as leis) e
apenas daí pode brotar o verdadeiro conhecimento.

A filosofia de Bacon propunha uma ciência neutra, onde a subjetividade encontrada no processo de elaboração de hipóteses e de pré-concepções pelo pesquisador não exercia um papel relevante no desenvolver da atividade científica, pois poderia contaminar a investigação a ser realizada, ou seja, qualquer interpretação prévia, na concepção Baconiana, possivelmente iria distorcer a percepção dos fenômenos e do mundo.

Essa epistemologia empirista-indutivista foi fortemente criticada por filósofos da ciência contemporâneos como Popper (1996), Kuhn (1997), Lakatos (1979), Feyerabend (2007), Bachelard (1984) e Laudan (1986). A mesma não se restringe ao campo da epistemologia, ela também está disseminada no contexto escolar e no ensino de ciências. Todavia, essa imagem tradicional da ciência por ser considerada ultrapassada e equivocada, uma vez que,

[...] defende o papel da observação e da experimentação "neutra" (não contaminadas por ideias aprioritistas), esquecendo o papel essencial das hipóteses como focalizadoras da investigação e dos corpos coerentes de conhecimentos (teorias) disponiveis, que orientam todo o processo (CACHAPUZ et al, p.43, 2005).

Dentre os epistemólogos citados, o físico e filósofo Thomas Kuhn, em sua principal obra "A Estrutura das Revoluções Científicas", apresenta argumentos contrários ao método científico proposto por Bacon e propõe que a ciência se desenvolve por meio de uma sucessão de períodos de ciência normal, interrompidos por revoluções científicas. Nos períodos de ciência normal, a academia adere a um paradigma ${ }^{1}$, enquanto que, nos períodos de revoluções científicas, o paradigma vigente sofre uma ruptura. Durante o processo de transição, o antigo e o novo paradigma disputam a preferência dos membros da comunidade científica, que por sua vez, apresentam distintas visões de mundo. $O$ trabalho de Kuhn consiste em um importante marco para a construção e consolidação de uma imagem contemporânea e mais coerente da ciência (OSTERMANN, 1996).

O trabalho do francês Gaston Bachelard (1884-1962) também foi fundamental tanto para o campo da ciência quanto da epistemologia. Apesar de não se deter a publicar textos essencialmente voltados para a área educacional, Bachelard 
propõe análises de cunho filosófico com interpretações acerca do conhecimento científico no ambiente escolar. Um dos aspectos mais importantes na concepção de Bachelard é o conceito de obstáculos epistemológicos ou barreiras epistemológicas que dizem respeito, de modo bastante simplificado, a um impedimento de que um indivíduo assimile um novo conhecimento devido, possivelmente, a experiência imediata do senso comum (OSTERMANN; CAVALCANTI, 2011).

Nesta perspectiva, pode-se considerar que o progresso da ciência está diretamente relacionado à superação dos obstáculos epistemológicos, oriundos do senso comum, das experiências perceptíveis e diretas e também dos conhecimentos acumulados e para superá-los é preciso que haja, muitas vezes, uma ruptura com conhecimentos anteriores, reestruturando o novo conhecimento (OSTERMANN; CAVALCANTI, 2011).

Para Bachelard, "o conhecimento do real é luz que sempre projeta algumas sombras" e o conhecimento empírico é responsável por muitos erros, porém, como já mencionado, a retificação dos mesmos é fundamental à formação do espírito científico, uma vez que "os erros são necessários e inevitáveis, pois refletem os períodos de estagnação, inércia e até regressão com que se depara o espírito científico" (MELO, 2005, p.45). Nas palavras de Lopes (1996, p.252-253)

Bachelard defende que precisamos errar em ciência, pois o conhecimento científico só se constrói pela retificação desses erros. Como seu objetivo não é validar as ciências já prontas, tal qual pretendem os partidários das correntes epistemológicas lógicas, o erro deixa de ser interpretado como um equívoco, uma anomalia a ser extirpada. Ou seja, com Bachelard, o erro passa a assumir uma função positiva na gênese do saber e a própria questão da verdade se modifica. Não podemos mais nos referir à verdade, instância que se alcança em definitivo, mas apenas às verdades, múltiplas, históricas, pertencentes à esfera da veracidade, da capacidade de gerar credibilidade e confiança. As verdades só adquirem sentido ao fim de uma polêmica, após a retificação dos erros primeiros.

Bachelard ainda afirma que "para o espírito científico, todo conhecimento é resposta a uma pergunta. Se não há pergunta, não pode haver conhecimento científico. Nada é evidente. Nada é gratuito. Tudo é construído" (BACHELARD, 2005, p.18). É necessário, portanto, que se faça perguntas, pois quando há questionamento, há também a construção de conhecimento.

Uma das importantes contribuições de Bachelard, além de empenhar-se com as questões do conhecimento, diz respeito a sua constante preocupação com o processo de ensino e aprendizagem na escola, pois, conforme esclarece Bulcão (1981, p.17),

A Epistemologia Histórica de Bachelard: “(...) conseguiu explicar as transformações que afetaram as teorias científicas contemporâneas. Como se sabe, o surgimento de novas teorias como a relatividade, a mecânica quântica e ondulatória e as novas geometrias, causou um abalo na noção de verdade científica, pois estas contrariavam muitos princípios básicos da ciência existente. Bachelard é atual, no sentido de que vai refletir sobre essa ciência que está surgindo, analisando suas contradições internas, e seu processo de racionalização. A Epistemologia bachelardiana é adequada à ciência contemporânea, porque ela analisa o trabalho concreto dos cientistas de hoje, em lugar de falar de uma ciência abstrata e atemporal" 
Nesse sentido, pode-se assegurar que as rupturas e descontinuidades, tão presentes na história das ciências naturais, são essenciais para que ocorra a evolução do pensamento científico. A revolução Copernicana, por exemplo, referese a um processo histórico que culminou na substituição do modelo geocêntrico (geocentrismo) pelo modelo heliocêntrico (heliocentrismo) representa rupturas que corroboraram para uma nova concepção de mundo que trazia consigo profundas mudanças para a história da humanidade, tanto para a ciência, quanto para a religião.

Ainda para Bachelard (1975) a cultura científica contemporânea carece de novas bases filosóficas, na proporção em que o conhecimento comum sofre rupturas. Nesse sentido, é importante que se reflita sobre qual perspectiva epistemológica os currículos escolares estão pautados.

Diante da breve explanação percebe-se que não existe um único método que norteia a atividade científica, bem como é possível perceber que as concepções epistemológicas do século XX podem trazer importantes implicações para o ensino, contudo a transposição destes pressupostos para a sala de aula, por meio das orientações educacionais não é uma tarefa fácil, devido à complexidade de se inserir de modo efetivo e contextualizado a história da ciência no ambiente educacional.

Matthews (1995, p. 172-173) destaca que a história da ciência contribui para o ensino por diversos motivos, entre eles:

(1) Motiva e atrai os alunos; (2) humaniza a matéria; (3) promove uma compreensão melhor dos conceitos científicos por traçar seu desenvolvimento e aperfeiçoamento; (4) há um valor intrínseco em se compreender certos episódios fundamentais na história da ciência - a revolução científica, o darwinismo, etc.; (5) demostra que a ciência é mutável e instável e que, por isso, o pensamento científico atual está sujeito a transformações que (6) se opõe a ideologia científica; e, finalmente, (7) a história permite uma compreensão mais profícua do método científico e apresenta os padrões de mudança na metodologia vigente.

Deste modo, ao entender que a história da ciência tem uma história pautada na contribuição de muitas bases filosóficas e epistemológicas é importante que se busque também entender de que forma a história da ciência, em especial a história da Física está presente nos documentos oficiais que orientam a prática docente dos professores do estado do Paraná.

As Orientações Educacionais Complementares aos Parâmetros Curriculares Nacionais $(\mathrm{PCN}+)$ apresentam como uma das competências da área da Ciência da Natureza, a Ciência e tecnologia na história, que tem como objetivo "Compreender o conhecimento científico e o tecnológico como resultados de uma construção humana, inseridos em um processo histórico e social" (BRASIL, 2002, p. 67).

Para a disciplina de Física os objetivos que contemplam essa competência são ainda mais específicos e podem ser executados ao longo de todo o ensino médio, uma vez que consideram as seguintes finalidades:

- Compreender a construção do conhecimento físico como um processo histórico, em estreita relação com as condições sociais, políticas $\boldsymbol{e}$ econômicas de uma determinada época. Compreender, por exemplo, a transformação da visão de mundo geocêntrica para a heliocêntrica, relacionando-a às transformações sociais que the são contemporâneas, 
identificando as resistências, dificuldades e repercussões que acompanharam essa mudança.

- Compreender o desenvolvimento histórico dos modelos físicos para dimensionar corretamente os modelos atuais, sem dogmatismo ou certezas definitivas.

- Perceber o papel desempenhado pelo conhecimento físico no desenvolvimento da tecnologia e a complexa relação entre ciência $\boldsymbol{e}$ tecnologia ao longo da história. Muitas vezes, a tecnologia foi precedida pelo desenvolvimento da Física, como no caso da fabricação de lasers, ou, em outras, foi a tecnologia que antecedeu o conhecimento científico, como no caso das máquinas térmicas.

\begin{abstract}
- Compreender o desenvolvimento histórico da tecnologia, nos mais diversos campos, e suas consequências para o cotidiano e as relações sociais de cada época, identificando como seus avanços foram modificando as condições devida e criando novas necessidades. Esses conhecimentos são essenciais para dimensionar corretamente o desenvolvimento tecnológico atual, através tanto de suas vantagens como de seus condicionantes. Reconhecer, por exemplo, o desenvolvimento de formas de transporte, a partir da descoberta da roda e da tração animal, ao desenvolvimento de motores, ao domínio da aerodinâmica e à conquista do espaço, identificando a evolução que vem permitindo ao ser humano deslocar-se de um ponto ao outro do globo terrestre em intervalos de tempo cada vez mais curtos e identificando também os problemas decorrentes dessa evolução (BRASIL, 2002, p. 67, grifo nosso).
\end{abstract}

Tais objetivos vão ao encontro de uma visão de ciência contextualizada com o contexto histórico, político, social e econômico em que os conhecimentos físicos de desenvolveram. Segundo Cachapuz et al essa ruptura das noções de pendor empirista/endutivista, "[...] importa que os alunos possam tomar consciência da construção dinâmica do conhecimento, das suas limitações, da constante luta em busca da verdade e não de certezas (CACHAPUZ et al, p.73, 2005).

Com propósito de auxiliar o professor na elaboração de suas aulas, as orientações sugerem caminhos que podem fornecer subsídios para o alcance das diversas competências, por meio de seis temas estruturantes, tais como: movimentos: variações e conservações; calor, ambiente e usos de energia; som, imagem e informação; equipamentos elétricos e telecomunicações; matéria e radiação; Universo, Terra e vida. Ao visar à inserção da história da Ciência no currículo de Física por meio da contextualização da ciência e tecnologia nesses temas estruturantes foram encontrados poucos elementos para a concretização dessa competência.

No que se refere ao primeiro tema estruturante 'movimentos: variações e conservações' destaca-se que "[...] são desse âmbito a compreensão da evolução tecnológica relacionada às máquinas mecânicas e suas transformações ao longo dos tempos" (BRASIL, 2002, p. 72, grifo nosso). Essa descrição nos remete ao entendimento da historicidade que envolve a tecnologia em relação a máquinas mecânicas, indo além da matematização das variações dos movimentos e suas conservações.

O segundo tema estruturante 'calor, ambiente e usos de energia' evidencia a necessidade para "[...] mais atenção aos aspectos propriamente termodinâmicos, envolvendo o funcionamento de máquinas térmicas, o próprio conceito de calor e modelos explicativos sobre seu trânsito na matéria, seja no aspecto 
macroscópico ou microscópico" (BRASIL, 2002, p. 73, grifo nosso). Fica subentendido a importância em ir além de uma única definição do conceito do calor, bem como, de um modelo explicativo, mostrando a possibilidade de abordar a evolução desse conceito ao longo da história e os diferentes modelos aceitos na academia científica.

Para uma compreensão mais específica desse tema, a unidade temática quatro destaca a importância em "acompanhar a evolução da produção, do uso social e do consumo de energia, relacionando-os ao desenvolvimento econômico, tecnológico e à qualidade de vida ao longo do tempo" (BRASIL, 2002, p. 74, grifo nosso), enfatizando que a ciência é uma construção histórica e social.

Em relação ao terceiro tema estruturante 'som, imagem e informação', o documento destaca que

O estudo do som e da imagem pode propiciar, ainda, meios para dimensionar o papel da informação para a vida social, acompanhando as transformações sociais que resultaram do domínio tecnológico, do registro, reprodução $e$ velocidade de transmissão de informações ao longo da história (BRASIL, 2002, p. 75, grifo nosso).

Por meio desse recorte, pode-se perceber que é necessário ir além dos conteúdos tradicionalmente abordados em sala de aula, principalmente no referese a som e imagem, uma vez que a informação está interligada e reflete diretamente na compreensão histórica do desenvolvimento da sociedade. É importante que tal compreensão histórica se de nos moldes da visão de ciência compartilhada pelos epistemólogos do século XX, como Kuhn e Bachelard, pois é fundamental que os estudantes entendam a ciência como uma construção humana, isto é, que ela seja empregada como um subsídio teórico para um ensino construtivista, sendo que, "[...]ser construtivista é uma postura que implica coerência: assim como encaramos o aluno como construtor de sua estrutura cognitiva, devemos transmitir a ele uma visão construtivista de ciência" (OSTERMANN; CAVALCANTI, 2011, p.46).

A abordagem histórica não é evidenciada nos temas estruturantes quatro e cinco que se refere aos 'equipamentos elétricos e telecomunicações' e 'matéria e radiação'. Contudo, no sexto tema estruturante aparece de modo muito expressivo ao destacar que

\begin{abstract}
Esses assuntos podem permitir reconhecer a presença da vida humana no Universo como uma indagação filosófica e também das condições físicas, químicas e biológicas para sua existência, evidenciando as relações entre ciência e filosofia ao longo da história humana, assim como a evolução dos limites para o conhecimento dessas questões (BRASIL, 2002, p. 79, grifo nosso).
\end{abstract}

Em contrapartida, o estado do Paraná apresenta em sua Diretriz Curricular de Física, apenas três temas estruturantes, entre eles: movimento, termodinâmica, eletromagnetismo. Ao analisar a relação desses temas com a inserção da História da Ciência percebe-se uma linguagem muito superficial. $O$ primeiro tema 'Movimento' o descreve, afirmando que 
Energia, desenvolvida nos estudos da termodinâmica, no século XIX, e considerada uma das mais importantes leis da Física (PARANÁ, 2008, p. 58, grifo nosso).

O parágrafo apresentado enfatiza a necessidade em abordar expostos que envolvem a conservação de momentum e energia detalhando a importância dos aspectos do século XIX, contudo não esclarecem a necessidade de evidenciar a construção história, filosófica e social para o entendimento destas ideias, podendo assim transmitir uma imagem de ciência denominada por Gil-Pérez et al (2001) como aproblemática e ahistórica de modo que

[...] transmitem-se os conhecimentos já elaborados, sem mostrar os problemas que lhe deram origem, qual foi a sua evolução, as dificuldades encontradas etc., e não dando igualmente a conhecer as limitações do conhecimento cientifico atual nem as perspectivas que, entretanto, se abrem (GIL-PÉREZ et al, 2001, p. 131).

Em relação ao segundo tema 'termodinâmica' destaca-se a importância em apresentar trabalhos de renomados cientistas que contribuíram para a formulação das primeiras ideias da conservação de energia. Ou seja, de acordo com as diretrizes:

No campo da Termodinâmica, os estudos podem ser desdobrados a partir das Leis da Termodinâmica, em que aparecem conceitos como temperatura, calor (entendido como energia em trânsito) e as primeiras formulações da conservação de energia, sobretudo os trabalhos de Mayer, Helmholtz, Maxwell e Gibbs (PARANÁ, 2008, p. 58, grifo nosso).

O terceiro e último tema 'eletromagnetismo' enfatiza a significância da História no Ensino ao afirmar que

Historicamente, um dos resultados mais importantes dos trabalhos de Maxwell é a apresentação da luz como uma onda eletromagnética e o estudo das suas equações que levam às quatro leis do Eletromagnetismo Clássico (PARANÁ, 2008, p. 60).

A teoria elaborada por Maxwell deu à natureza ondulatória da luz uma sólida envergadura teórica. Todavia, trabalhos realizados no final do século XIX e início do século $X X$, especialmente por Planck e Einstein, levaram ao estabelecimento da natureza corpuscular - os quanta da luz - que revelaram a natureza dual da luz. (PARANÁ, 2008, p. 61, grifo nosso).

Observa-se que nesse tema é expresso com maior evidência à historicidade do conteúdo, contudo, limita-se aos trabalhos de um único cientista da Física clássica, acarretando assim em uma possível visão individualista e elitista, segundo a qual "os conhecimentos científicos aparecem como obras de gênios isolados, ignorando-se o papel do trabalho coletivo e cooperativo, dos intercâmbios entre equipes" (GIL-PÉREZ et al, 2001, p. 133). Além disso, é importante abordar aspectos referentes à ciência e a tecnologia imbricados do decorrer da história para o entendimento do desenvolvimento tecnológico em que a sociedade atual está inserida, uma vez que 
Mediante as reformas que estão ocorrendo do Ensino Médio, como a implementação da Base Nacional Curricular Comum (BNCC), torna-se imprescindível analisar este documento para o entendimento de como a história da Ciência está sendo vista nos documentos atuais, contudo, ressalva-se que este documento ainda está em elaboração e para a análise foi utilizado a 2a versão.

A Base Nacional Curricular Comum tem como propósitos diversos objetivos que contemplam os diferentes eixos de formação. O primeiro objetivo expressa claramente a história da ciência no ensino ao afirmar a importância de "Apropriarse da cultura científica como permanente convite à dúvida, reconhecendo-a como um empreendimento humano, portanto, histórico e social, e considerando seus princípios como sínteses provisórias de uma construção ininterrupta" (BRASIL, 2016. p. 587, grifo nosso).

Ao destacar a expressão grifada, observa-se que essa ideia vai ao encontro de Martins (2006), visto que, para ele "as teorias científicas vão sendo construídas por tentativa e erro, elas podem chegar a se tornar bem estruturadas e fundamentadas, mas jamais podem ser provadas" (MARTINS, 2006, p. 23).

Para alcançar esses objetivos o documento descreve as expectativas para cada uma das disciplinas curriculares do Ensino Médio. No que se refere à História da Ciência na Física é possível observar a importância em ser ensinada, ou seja, para a BNCC

\footnotetext{
É fundamental que esse corpo organizado de conhecimentos seja percebido em sua dinamicidade histórica e social. Trata-se de um conhecimento que se desenvolveu - e se desenvolve - em diálogo constante com o mundo natural e social, em um processo marcado por rupturas e continuidades, no qual conhecimentos anteriores são, por vezes, ampliados, mas em muitos aspectos superados ao longo do tempo. (BRASIL, 2016. p. 587, grifo nosso).
}

A BNCC deixa esclarecido que a Física pertence há uma construção histórica social marcada por rupturas e continuidades, bem como por ideias superadas ao longo do tempo, ou seja, "a Física integra, desse modo, a cultura em seu sentido amplo e deve ser tratada em contextos históricos, sociais que, ao lado de outros saberes, constituem um segundo eixo formativo para o aprendizado da Física" (BRASIL, 2016. p. 587, grifo nosso). De acordo com Chalmers (1993, p. 60)

[...] é essencial compreender a ciência como um corpo de conhecimento
historicamente em expansão e que uma teoria só pode ser adequadamente
avaliada se for prestada a devida atenção ao seu contexto histórico. A
avaliação da teoria está intimamente ligada às circunstâncias nas quais surge.

Observa-se também que o documento faz uso do verbo dever, ressaltando, deste modo, que o professor tem compromisso em inserir elementos da história da ciência ao longo do ensino médio. Esta orientação pode vir a auxiliar o rompimento de uma imagem algorítmica e exata da ciência, evidenciando as controvérsias e as revoluções científicas (GIL-PÉREZ, 2001).

Em relação à organização curricular da componente Física para o Ensino Médio é perceptível que o documento a divide em 6 temas estruturantes: movimentos dos objetos e sistemas, energias e suas transformações, processos de comunicação e informação, eletromagnetismo - materiais e equipamentos, matéria e radiações - constituições e interações, Terra e Universo - formação e evolução. Todos os temas têm uma descrição breve, mas ampla sobre o assunto, 
de modo que as escolas e os professores continuam com liberdade para desenvolverem os conteúdos em sala de aula (BRASIL, 2016).

Os elementos de História da Ciência aparecem discretamente nas descrições, contudo, de forma incisiva. Com isso, é possível observar a estreita relação entre os documentos oficias e a academia, uma vez que, de acordo com Martins (2006), a história da ciência pode contribuir na aprendizagem dos conteúdos científicos. $O$ primeiro tema 'movimentos dos objetos e sistemas' destaca a necessidade de questionar

[...] como movimentos são produzidos, mantidos e alterados e como forças se relacionam com movimentos e equilíbrios, em situações práticas e como formulação abstrata. Discute-se espaço, tempo e sua interdependência. Apresentam-se princípios universais que valem para interações com qualquer tipo de força, em qualquer fenômeno ou processo. Revela-se como essas compreensões tem mudado ao longo da história. (BRASIL, 2016. p. 589, grifo nosso).

O segundo tema remete que

\begin{abstract}
A energia é estudada em todas as suas manifestações, mostrando-se que sempre se conserva, mas inevitavelmente se degrada. A termodinâmica, surgida há séculos na sistematização de maquinas, configura e interpreta propriedades térmicas, conceitua calor e trabalho em trocas de energia. Analisam-se processos naturais e tecnológicos e questionam-se desequilibrios ambientais pela crescente exploração de recursos naturais. (BRASIL, 2016. $p$. 590, grifo nisso).
\end{abstract}

Nestes dois primeiros temas os aspectos relacionados a história da ciência referem-se a conteúdo específicos, porém sugere-se que os mesmos estejam relacionados com as complexas relações entre ciência, tecnologia, sociedade (CTS). Nesse prisma, Martins (2006) enfatiza essa importância ao afirmar que

O estudo adequado de alguns episódios históricos permite compreender as interrelações entre ciência, tecnologia e sociedade, mostrando que a ciência não é uma coisa isolada de todas as outras, mas sim faz parte de um desenvolvimento histórico, de uma cultura, de um mundo humano sofrendo influências e influenciando por sua vez muitos aspectos da sociedade (MARTINS, 2006, p. 2122)

Em relação ao terceiro tema a BNCC descreve que

Sistemas e processos de comunicação, informação e de registro $e$ processamento de informações são analisados como parte da cultura, desde papiros e telégrafos a CDs e internet. Promove-se a compreensão desses sistemas, em seus aspectos acústicos e óticos básicos na produção e modulação de ondas em faixas de frequência e sua emissão de diferentes formas. Discutem-se aspectos sociais e culturais da evolução dessas práticas, deixando-se para a próxima unidade a materialidade eletromagnética dos dispositivos. (BRASIL, 2016. p. 590, grifo nosso).

Já no quinto tema,

A constituição submicroscópica da matéria é investigada, a partir da sistematização das radiações eletromagnéticas, como gama, ou corpusculares como alfa, beta e gama, cuja analise revela a estrutura do núcleo atômico, com atenção também para a sucessão histórica de modelos 
para a composição infinitesimal das substancias. O emprego das radiações em aplicações diagnosticas e terapêuticas, na produção de energia ou em artefatos bélicos do contexto para se compreender fissão e fusão nuclear, que serão fundantes para a astrofísica e cosmologia da próxima Unidade (BRASIL, 2016. p. 590-591).

Em ambos os temas é apresentado a relevância de se inserir a história da ciência no ensino, seja por meio da necessidade de abordar historicamente os registros dos meios de informação os relacionando com aspectos sociais e culturais, ou seja, pela importância de discutir elementos que subsidiam a construção histórica dos modelos de composição infinitesimal das substâncias, bem como, os aspectos relacionados à matéria e as radiações eletromagnéticas.

Ainda sobre o terceiro tema, o texto proposto pela BNCC faz referência a influência da sociedade e da cultura na evolução dos conteúdos, práticas e conceitos, indo ao encontro das ideias de Martins (1990, p. 4), uma vez que

Sob o ponto de vista didático (ou de tática de ensino), a História de Ciência tem várias aplicações. Ela pode ser usada para contrabalançar os aspectos puramente técnicos de uma aula, complementando-os com um estudo de aspectos sociais, humanos e culturais.

Ostermann e Cavalcanti (2011, p.25) complementam essa ideia ao afirmarem que os

[..] estudos que levam em conta os aspectos socioculturais e trabalham adequadamente com as diferentes visões de mundo e com as interações discursivas entre os estudantes em sala de aula podem, com certeza, ajudar a melhorar muito o ensino de Física e de outras ciências.

Para finalizar a análise deste documento, o quarto e o sexto tema estruturante não apresentam aspectos relacionados à história da ciência. As descrições feitas nos mesmos remetem-se a questões de conteúdo e atualidades.

Mediante ao que foi explanado sobre os documentos oficiais percebe-se que os currículos brasileiros estão com o mesmo direcionamento dos documentos dos demais países destacados no início do texto, uma vez que Matthews (1995, p. 188) ressalva que "os episódios da história da ciência e as questões acerca da natureza (filosofia) da ciência são parte integrantes desses currículos" e esse mesmo ideal está presente nas diretrizes brasileiras.

De acordo Martins (2006) a história da ciência está conquistando espaço, tanto no nível médio, por conta da mesma estar inserida nos documentos oficiais e no ensino superior. Contudo, o autor destaca que ainda existem obstáculos para que ela seja incorporada efetivamente no ensino, de modo que, ele enfatiza três desses obstáculos a luz de Siegel (1979):

(1) Carência de um número suficiente de professores com a formação adequada para a pesquisar e ensinar de forma correta a história das ciências; (2) a falta de material didático adequado (textos sobre história da ciência) que possa ser utilizado no ensino; e (3) equívocos a respeito da própria natureza da história da ciência e seu uso na educação. (SIEGEL, 1979 apud MARTINS, 2006, p. 27).

Em referência ao primeiro obstáculo, Martins (2006) acredita que as universidades brasileiras precisam oferecer mais cursos de pós-graduação em 
história da ciência, bem como mobilidades com os centros de pesquisa em outros países da área. E acrescenta que "deve-se ter em mente que os professores improvisados podem prestar um grande desserviço a essa área" (MARTINS, 2006, p. 27).

No segundo obstáculo, o problema não está na quantidade de materiais relacionados a história da ciência em português, mas a qualidade em que os mesmos são produzidos, uma vez que existem escritores improvisados que se referenciam em obras não especializadas e de fontes duvidosas, como enciclopédias e internet (MARTINS, 2006). Nessa perspectiva, o autor define como um bom livro de história da ciência, aquele que

[...] além de ser escrito por quem entende do assunto, deve ser o resultado de um trabalho de pesquisa, do estudo dos melhores estudos já feito sobre o tema e da literatura das obras originais (literatura primária) que estão sendo descritas. (MARTINS, 2006, p. 28).

Ou seja, um livro de história da ciência para ser utilizado no ensino apresenta uma linguagem apropriada e de acordo com o público alvo, explicando sem simplificar, mas também se formalidades acadêmicas, ou seja, apresentando a complexidade histórica real de maneira didática (MARTINS, 2006).

Já o terceiro obstáculo, é diretamente relacionado com os anteriores, uma vez que há muita concepção erronia sobre a própria natureza da história da ciência (MARTINS, 2006). O uso inadequado da mesma no ensino acarreta diferentes empecilhos, tais como: redução da história da ciência a nomes, a datas e anedotas; concepções errôneas sobre o método científico; uso de argumentos de autoridade, entretanto, há apenas uma maneira apropriada para a imersão do conhecimento científico e está se dá por meio do estudo da história da ciência (MARTINS, 2006).

Nessa perspectiva, Martins (2006, p. 31) acrescenta que

Há muitas armadilhas, e exige-se o uso do conhecimento epistemológico e historiográfico especializado para evitar alguns erros que poderiam levar o professor a empregar erroneamente a história da ciência para transmitir uma ideia de ciência totalmente inadequada, como ocorre muitas vezes. É necessário, por isso, um trabalho de pesquisa para fundamentar um adequado uso da história da ciência no processo educacional.

Mediante ao que foi explanado percebe-se que abordar a história da ciência no ensino é uma atividade complexa, mas aos poucos está sendo incorporada na educação básica brasileira, uma vez que, os documentos oficiais enfatizam essa necessidade, contudo, ainda é necessário superar as três barreiras evidenciadas para que a inserção da história da ciência aconteça de maneira eficaz e de qualidade.

\section{CONSIDERAÇÕES FINAIS}

Os três documentos oficiais discutidos no texto apontam para a necessidade de inserção da História da Ciência no ensino de Física, porém estes diferem na profundidade de suas abordagens. Aparentemente, os documentos buscam romper com uma concepção empirista-indutivista seguindo uma sequência rígida, linear e indutiva, bem como com as interpretações errôneas sobre a produção do 
conhecimento científico. Todavia, a história da ciência é apresentada de modo periférico e generalizado e, por vezes até ingênuo, pois, o termo "evolução" que constantemente está presente no texto pode ser entendido como uma postura linear e acumulativa, não fornecendo assim, subsídios teóricos para o professor de Física inseri-la efetivamente, visando uma formação que propicie a compreensão do conhecimento enquanto construção sócio-histórica, evidenciando o caráter humano da ciência.

Ademais, pode-se perceber, por meio da análise da mais recente proposta educacional, a BNCC, que a História da Ciência está sendo concebida como uma necessidade emergente que visa orientar mais incisivamente a prática docente do professor de Física na direção de promover mudanças que contemplem a formação desejada para o presente século. 


\title{
The History of Science in the Curriculum of High School Physics
}

\begin{abstract}
This work has the purpose of showing how the Science history is present in three official documents: The complementary Educational Orientations to the National Curricula Parameters, the Physics Curricular Guideline and the Common Curricular National Base. Through this article, it is sought to aid the physics teacher to know and comprehend such guidelines for being performed in his teaching career. The procedures of the analyses have consisted in searching for textual elements which covered the theme "History of Science" and "History of Physics". As a result, it was noticed that there is an expressive input of the theme in the last past years, as the documents are being updated. The History of Science was gradually more being inserted in the documents, therefore in discreet and generalized way. It concludes, however, that the History of Science is moving, but at slow motion, thus making difficult its wide implementation in High School.
\end{abstract}

KEYWORDS: The History of science. History of physics. Curriculum. Public politics. 


\section{NOTAS}

1 De acordo com Romanowsk e Ens (2006), esse tipo de estudo objetiva a sistematização da produção numa determinada área do conhecimento. Quando o levantamento aborda apenas um setor. 


\section{REFERÊNCIAS}

BACHELARD, G. A filosofia do não. Lisboa: Presença, 1984.

2005.

. A Formação do Espírito Científico.5. ed. Rio de Janeiro: Contraponto,

. La Actividad Racionalista de la Física Contemporanea. Buenos Aires:

Editorial Siglo Veinte, 1975.

BACON, F. Novum Organum ou Verdadeiras Indicações Acerca da Interpretação da Natureza. São Paulo: Nova Cultural Cultural, 1999. (Trad. José A. R. Andrade), (Coleção Os Pensadores).

BRASIL. Ministério da Educação. Base Nacional Curricular Comum. 2a versão. Brasília: MEC, 2016.

BRASIL. Secretaria da Educação Fundamental. Orientações Educacionais Complementares aos Parâmetros Curriculares. Brasília: MEC/SEF, 2002.

BULCÃO, M. O Racionalismo da Ciência Contemporânea: Uma Análise da Epistemologia de Gaston Bachelard. Rio de Janeiro: Antares, 1981.

CACHAPUZ, A; GIL-PÉREZ, D; PRAIA, J; VILCHES, A. A necessária renovação no ensino de ciências. 3. ed. São Paulo: Cortez, 2011.

FEYERABEND, P. Contra o método. São Paulo: UNESP, 2007.

GIL-PÉREZ, D; MONTORO, I.F; ALÍS, J.C; CACHAPUZ, A; PRAIA, J. Para uma imagem não deformada do trabalho científico. Ciência \& Educação, v.7, n.2, p.125-153, 2001.

KUHN, T. A estrutura das revoluções científicas. São Paulo: Perspectiva, 1997.

LAKATOS, I. O falseamento e a metodologia dos programas de pesquisa científica. In: LAKATOS, I.; MUSGRAVE, A. (Eds.). A crítica e o desenvolvimento do conhecimento. São Paulo: EDUSP, 1979.

MARTINS, R. A. Introdução: a história das ciências e seus usos na educação. In aplicação no ensino. São Paulo: Editora Livraria da Física, 2006, p. 17-25. 
MARTINS, R. A. Sobre o papel da história da ciência no ensino. Boletim da Sociedade Brasileira de História da Ciência, n 9 p.3-5. 1990.

MATTHEWS, M.R. História e Filosofia e ensino de ciências: a tendência atual de reaproximação. Caderno Catarinense de Ensino de Física, v. 12, n. 3, p. 164-214, dez. 1995.

MELO, A.C.S. Contribuições da epistemologia histórica de Bachelard no estudo da evolução dos conceitos da óptica. 2005, 198f. Dissertação (Mestrado em Educação Científica e Tecnológica), Universidade Federal de Santa Catarina, Florianópolis.2005.

NEVES, M.C.D. A Questão Controversa da Cosmologia Moderna: Huble e o infinito-parte, Caderno Catarinense de Ensino de Física, v.17, n. 2, p. 189-204, 2000.

OSTERMANN, F. A epistemologia de Kuhn. Caderno Catarinense em Ensino Física, v.13, n3: p.184-196,1996.

OSTERMANN, F; CAVALCANTI, C.J.H. Epistemologia: implicações para o ensino de ciências. Porto Alegre: UFRGS, 2011.

PARANÁ, Secretaria de Estado da Educação. Diretrizes Curriculares de Física para a Educação Básica. Curitiba, 2008.

POPPER, K. A lógica da pesquisa científica. 6. ed. São Paulo: Cultrix, 1996.

Recebido: 29 mai. 2017

Aprovado: 29 ago. 2017

DOI: 10.3895/actio.v2n1.6790

Como citar:

CORREIO, M. R. M.; CORREIO, A. D. B. A História da Ciência no currículo de Física do Ensino Médio.

ACTIO, Curitiba, v. 2, n. 1, p. 420-437, jan./jul. 2017. Disponível em: <https://periodicos.utfpr.edu.br/actio>.

Acesso em: XXX.

Correspondência:

Milene Rodrigues Martins Correio

Rua José Clemente, 1274, ap. 103, Zona 7, Maringá, Brasil.

Direito autoral: Este artigo está licenciado sob os termos da Licença CreativeCommons-Atribuição 4.0

Internacional.

(c) (i) 